\title{
TET1 inhibits cell proliferation by inducing RASSF5 expression
}

\author{
Bo-Tai Li ${ }^{2}$, Chao $\mathbf{Y u}^{2}$, Ying $X u^{1}$, Sheng-Bing Liu ${ }^{1}$, Heng-Yu Fan ${ }^{2}$ and Wei-Wei Pan ${ }^{1}$ \\ ${ }^{1}$ Department of Cell Biology, College of Medicine, Jiaxing University, Jiaxing 314001, China \\ ${ }^{2}$ Life Sciences Institute, Zhejiang University, Hangzhou 301158, China \\ Correspondence to: Wei-Wei Pan, email: aidspan@163.com \\ Heng-Yu Fan, email: hyfan@zju.edu.cn \\ Keywords: ovarian cancer, TETI, RASSF5, proliferation, DNA methylation
}

Received: May 07, $2017 \quad$ Accepted: August 23, $2017 \quad$ Published: September 23, 2017

Copyright: Li et al. This is an open-access article distributed under the terms of the Creative Commons Attribution License 3.0 (CC BY 3.0), which permits unrestricted use, distribution, and reproduction in any medium, provided the original author and source are credited.

\section{ABSTRACT}

Tet methylcytosine dioxygenases (TETs) catalyze the oxidative reactions of 5-methylcytosine to 5-hydroxymethylcytosine $(5 \mathrm{hmC})$. However, TET1 roles in ovarian cancer cell growth are unknown. Here, we show that ectopic expression of TET1 increased $5 \mathrm{hmC}$ levels, and inhibited proliferation and colony formation in ovarian cancer cell lines. Furthermore, in vitro and in vivo functional studies demonstrated that TET1 overexpression is necessary for the suppression of ovarian cancer growth, whereas depletion of TET1 expression had the opposite effect. Furthermore, the results of RNA-seq and qRT-PCR analyses identified a tumor suppressor, Ras association domain family member 5 (RASSF5), as the key downstream target of TET1. TET1 promotes RASSF5 expression by demethylating a CpG site within RASSF5 promoter. Up-regulated RASSF5 expression leads to the suppression of ovarian cancer cells growth. Additionally, we demonstrated that inhibition of CUL4-DDB1 ubiquitin ligase complex decrease $5 \mathrm{hmC}$ levels in ovarian cancer cells. These results provide new insights into the understanding of how ovarian cancers develop and grow, and identify TET1 as a key player in this process.

\section{INTRODUCTION}

Ovarian cancer is the leading cause of death from all gynecological cancers [1]. However, mechanisms and factors regulating ovarian cancer growth and metastasis remain to be completely elucidated. Epigenetic alterations have long been linked to ovarian cancer initiation and progression, and they include DNA methylation changes and histone modifications. The best-characterized epigenetic mechanism is DNA methylation [2], which is crucial for gene silencing and transcriptional regulation of repetitive elements. DNA methylation occurs predominantly at $\mathrm{CpG}$ dinucleotides where DNA methyltransferases (DNMTs) mediate the transfer of a methyl group to cytosines, generating 5-methylcytosine $(5 \mathrm{mC})[3,4]$. Abnormal DNA methylation can lead to the development of genetic diseases such as Prader-Willi syndrome [5]. Moreover, during carcinogenesis, the methylation of $\mathrm{CpG}$ sites in the promoter region, together with genome-wide hypomethylation, leads to the silencing of tumor suppressor genes and activation of oncogenes, promoting cancer initiation and progression [6-8].

Previously, $5 \mathrm{mC}$ was considered the only modified base in animals, until the discovery of 5-hydroxymethylcytosine $(5 \mathrm{hmC})$ in bacteriophage and mammal DNA [9]. This epigenetic modification is catalyzed by the tet methylcytosine dioxygenase (TET) enzymes [10]. TET proteins mediate the sequential oxidation of $5 \mathrm{mC}$ to $5 \mathrm{hmC}$, leading to DNA demethylation [11]. Using anti-5hmC antibody-based immuno-dot-blot, it was demonstrated that $5 \mathrm{hmC}$ levels are greatly reduced in multiple cancer types, such as squamous cell lung cancers and brain tumors $[12,13]$, but the functional significance of this process has not been elucidated.

The TET family of DNA hydroxylases, which includes TET1, TET2, and TET3, mediates the conversion of $5 \mathrm{mC}$ to $5 \mathrm{hmC}$. TET expression was shown to be dysregulated in multiple malignances, including breast 
cancer, hepatocellular carcinoma, melanoma, and glioma [14-16]. TET1 was firstly identified as a fusion partner of mixed lineage leukemia (MLL) in acute myeloid leukemia (AML) $[17,18]$, and the downregulation of Tet 1 has been shown to promote cancer invasion and metastasis [19, 20]. TET2 gene was found to be mutated in cancers, leading to the loss of $5 \mathrm{hmC}$ [21]. Even though TET proteins have been shown to have an important role in cancer development, their roles in ovarian cancer are largely unknown.

In this study, we demonstrated that TET1 expression is downregulated in most ovarian cancer tissues and cells. Therefore, we examined how the dysregulation of TETI expression affects carcinogenesis, and aimed to determine the molecular mechanisms underlying these processes.

\section{RESULTS}

\section{$5 \mathrm{hmC}$ levels are decreased in ovarian cancer tissue and cells}

The levels and distribution of $5 \mathrm{hmC}$ in ovarian benign and malignant tumors were determined. As presented in Figure 1A, 5hmC levels were shown to be significantly higher in benign, compared with those in the malignant tumor samples. To confirm these results, we used two tissue arrays containing four normal ovarian tissue samples, five benign adenomas, 74 serous cystadenomas, 31 mucinous cystadenomas, 53 endometrioid carcinomas, and one clear cell cystadenoma sample (Table 1 and Supplementary Tables 1 and 2). Based on staining intensity, we classified the samples into five groups with increasing staining intensity from the weakest (-) to the strongest $(++++$; Figure 1B). As summarized in Figure 1C, strong nuclear $5 \mathrm{hmC}$ signal was observed in normal human ovarian samples and benign adenomas, whereas partial or complete loss of $5 \mathrm{hmC}$ staining was seen in almost in all primary and metastatic ovarian cancer cells.

Furthermore, we purified genomic DNA from ovarian cancer cells (SKOV3, A2780, ES-2, HO8910, OV2008, C13), other types of cancers (HeLa, Hep3132), or mOSE cells, and detected $5 \mathrm{hmC}$ levels using anti-5hmC antibody-based dot-blotting. The levels of this molecule were shown to be low in ES-2 and H08910 cells, but high in A2780 and OV2008 cells. HeLa cells transfected with TET3 plasmids were used as the positive control (Figure 1D), and these results demonstrated that $5 \mathrm{hmC}$ levels differ between ovarian cancer cell types. We confirmed that TET1 mRNA level was weakly expressed in HO8910 and ES-2 cells by quantitative RT-PCR (Figure 1E). At the protein level, as compared with other cells, TET1 was highly expressed in A2780 cells, but it was weakly expressed in ES-2 cell (Figure 1F), which was consistent with the observed $5 \mathrm{hmC}$ levels in ovarian cancer cells.

\section{Knockdown of TET1 or CUL4-DDB1 ubiquitin ligase complex decrease $5 \mathrm{hmC}$ levels in ovarian cancer cells}

TET1 is responsible for $5 \mathrm{mC}$ to $5 \mathrm{hmC}$ conversion, and we attempted to elucidate the effects of TET1 overexpression on $5 \mathrm{hmC}$ levels in ovarian cancer cells. We overexpressed TET1 or TET3 in A2780 cells and determined the levels of $5 \mathrm{hmC}$ using immunofluorescence staining. We observed a global increase in 5hmC levels in TET1 or TET3-overexpressing cells, but not in TET1-MU- or TET3-MU-overexpressing cells (Figure 2A). To demonstrate that TET increase $5 \mathrm{hmC}$ levels further, the effects of TET1 depletion in ovarian cancer cells were analyzed. Compared with control, siTET1 cells expressed significantly lower levels of TET1 (Figure 2B and 2C). Moreover, knockdown of TET1 significantly decreased 5hmC levels in A2780 cells (Figure 2D).

To identify the roles of CUL4-DDB1 E3 ligase complex in ovarian cancer cells, we performed a knockdown of CUL4-DDB1 E3 ligase components, ring of cullin-1 (ROC1), DDB1, or DDB1/CUL4-associated factor-1 $(D C A F 1)$ in A2780 cells, and detected $5 \mathrm{hmC}$ levels by dot-blot assays (Figure $2 \mathrm{E}$ and $2 \mathrm{~F}$ ). We found that the knockdown of these genes leads to a reduction in $5 \mathrm{hmC}$ levels in ovarian cancer cells. Moreover, MLN4924 was shown to be a potent inhibitor of cullin neddylation, and to inactivate CUL4-DDB1 E3 ligase complex, leading to the accumulation of its substrates [22, 23]. Here, MLN4924 treatment led to a decrease in 5hmC levels as well (Figure 2G).

\section{TET1 inhibits ovarian cancer cell growth and colony formation in vitro}

To elucidate the role of TET1 in ovarian cancer cell growth, ovarian cancer cells were infected with lentiviral LV-CON or LV-TET1. The expression of GFP-TET1-Flag was confirmed by western blot analysis (Figure 3A). The levels of $5 \mathrm{hmC}$ were shown to be significantly increased in TET1-overexpressing ovarian cancer cells, which was consistent with the results obtained using transient TET1 or TET3 overexpression (Figure 3B and 2A). We next analyzed the effect of TET1 overexpression on ovarian cancer cell proliferation and showed that this leads to a remarkable reduction in cell growth, compared with that in the control samples (Figure 3C). TET1-overexpressing ES-2 cells were shown to form a significantly lower number of colonies and their colony sizes were smaller than those in the control cells (Figure 3D-3F). In addition, TET1 gene silencing promoted A2780 cells growth and increase colonies number by colony forming assay (Figure $3 \mathrm{G}$ and $3 \mathrm{H})$. 


\section{TET1 suppresses tumor growth and promotes cancer cell apoptosis in vivo}

To evaluate the role of TET1 in tumor growth in vivo, we subcutaneously transplanted equal numbers of control ES-2 cells or ES-2 cells stably expressing TET1 into the left and right flanks of nude mice, respectively. We found that TET1-overexpressing tumors were significantly smaller than those in the control group. The weight of the tumors formed by TET1-overexpressing cells was fourfold lower than that of the control cells (Figure 4A). To confirm the transplanted cells are responsible for the tumor growth, western blot analysis demonstrated that most of the TET1-overexpressing tumor cells were positive for Flag-TET1 (Figure 4B). Afterwards, we determined 5hmC levels in tumor tissue samples and demonstrated that they were dramatically increased in TET1-overexpressing tumors (Figure 4C and 4D). Previous studies showed that TET1 can activate PARP-1/ARTD1 independently of DNA breaks and induce tumor cells apoptosis in multiple tissue types [24]. To elucidate the effects of TET1 on the ovarian cancer cell apoptosis, we measured $\mathrm{pH} 2 \mathrm{AX}$ and cleaved caspase 3 levels by IHC and immunofluorescence staining. We found that both $\mathrm{pH} 2 \mathrm{AX}$ and cleaved caspase
A

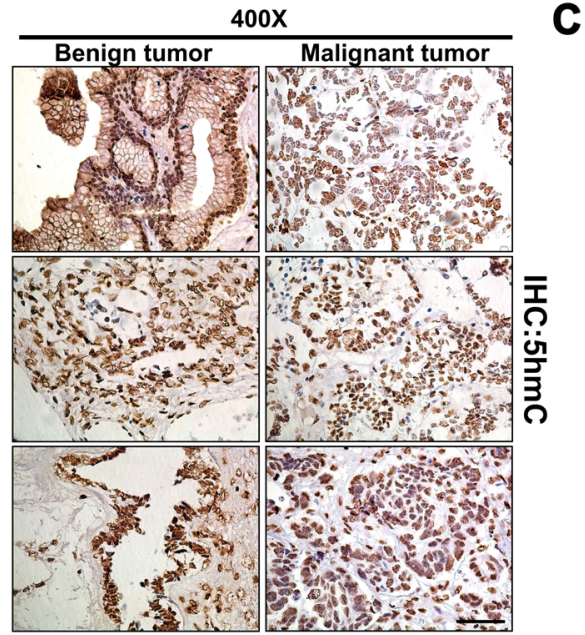

B
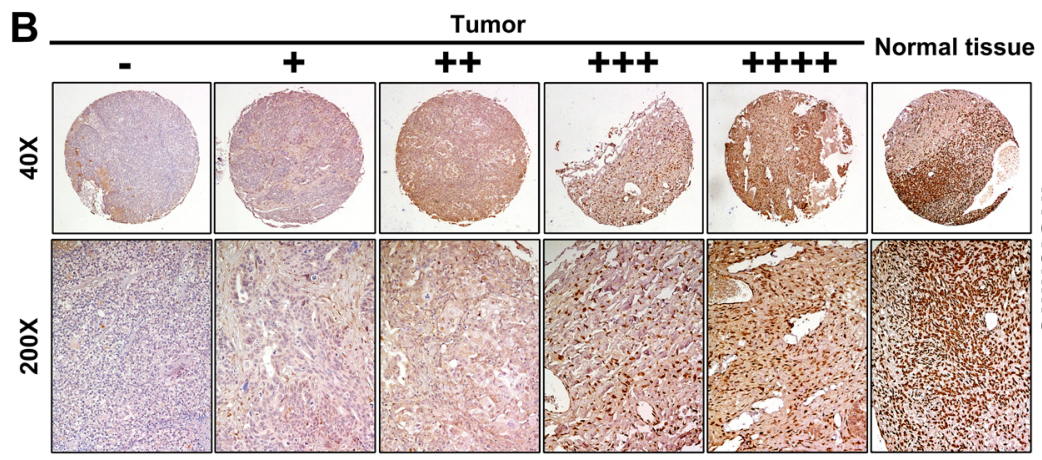

E
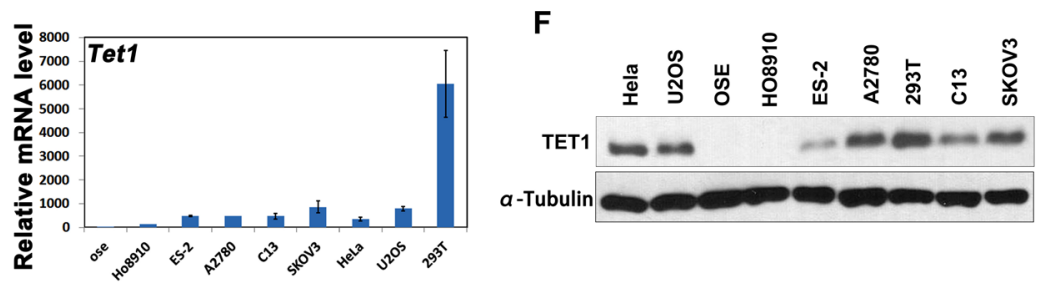

C

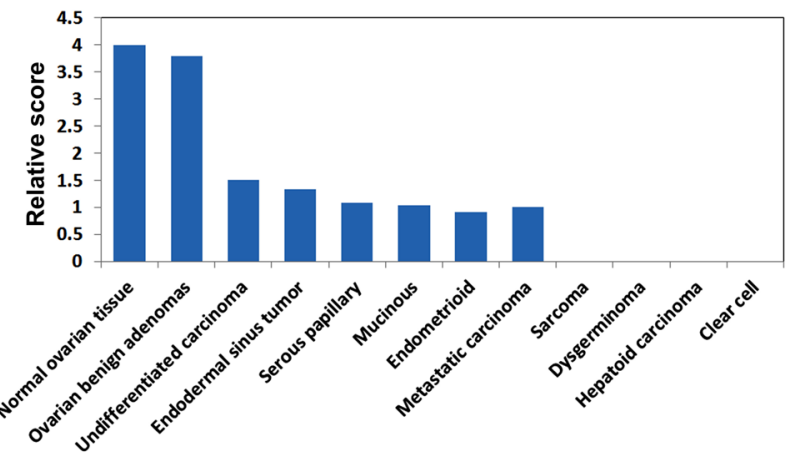

D

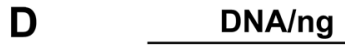

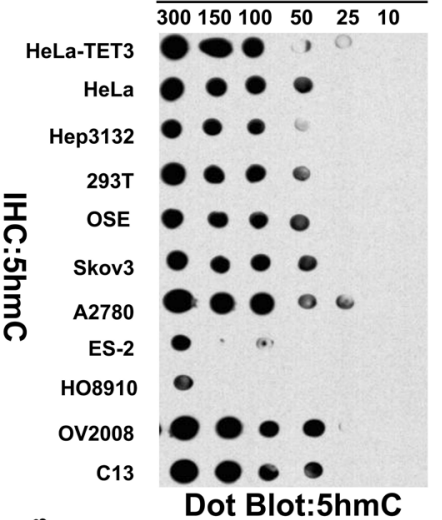

Dot Blot:5hmC

Figure 1: 5hmC production in human ovarian cancer samples and cells. (A) IHC analysis of $5 \mathrm{hmC}$ levels in human ovarian benign $(n=5)$ and malignant tumor tissue samples $(n=10)$. Sections were counterstained with hematoxylin. Scale bar, $50 \mu$ m. (B) Representative image of $5 \mathrm{hmC}$ staining (brown) in human ovarian cancer tissue samples with normal ovarian tissue ( $\mathrm{n}=177)$. (C) Quantification of relative TMA scores of the described human samples. (D) 5hmC expression in ovarian cancer cells (SKOV3, A2780, ES-2, HO8910, OV2008, and C13), Hep3132, 293T, immortalized mOSE cells, and HeLa cells in vitro. HeLa-TET3 was used as positive control. (E) Quantitative RT-PCR analysis of TET1 expression in the indicated cancer cells or primary cells. Results are represented as mean \pm standard error (SE) obtained in three independent experiments. (F) SKOV3, A2780, ES-2, HO8910, C13, U2OS, 293T, immortalized mOSE cells, and HeLa cells were subjected to immunoblot (IB) analysis with antibodies to TET1 and $\alpha$-Tubulin proteins. 
Table 1: $5 \mathrm{hmC}$ protein expression in ovarian cancer and normal ovary tissues

\begin{tabular}{|c|c|c|c|c|c|c|}
\hline \multirow[b]{2}{*}{$\begin{array}{l}\text { Ovarian cancer } \\
\text { type }\end{array}$} & \multicolumn{6}{|c|}{ Grade } \\
\hline & $\operatorname{Case}(N)$ & ++++ & +++ & ++ & + & - \\
\hline $\begin{array}{l}\text { Normal ovarian } \\
\text { tissue }\end{array}$ & 4 & $4(100 \%)$ & & & & \\
\hline $\begin{array}{l}\text { Ovarian benign } \\
\text { adenomas }\end{array}$ & 5 & $4(80 \%)$ & $1(20 \%)$ & & & \\
\hline $\begin{array}{l}\text { Undifferentiated } \\
\text { carcinoma }\end{array}$ & 2 & & & $1(50 \%)$ & $1(50 \%)$ & \\
\hline $\begin{array}{l}\text { Endodermal } \\
\text { sinus tumor }\end{array}$ & 3 & & & $1(33.33 \%)$ & $2(66.67 \%)$ & \\
\hline Serous papillary & 74 & $5(6.76 \%)$ & $4(5.41 \%)$ & $10(13.5 \%)$ & $28(37.84 \%)$ & $27(36.49 \%)$ \\
\hline Mucious & 31 & & $6(19.35 \%)$ & $4(12.91 \%)$ & $6(19.36 \%)$ & $15(48.39)$ \\
\hline Endometrioid & 53 & & $4(7.55 \%)$ & $10(18.86 \%)$ & $16(30.19 \%)$ & $23(43.4 \%)$ \\
\hline $\begin{array}{l}\text { Hepatoid } \\
\text { carcinoma }\end{array}$ & 1 & & & & $1(100 \%)$ & \\
\hline $\begin{array}{l}\text { Metastatic } \\
\text { carcinoma }\end{array}$ & 1 & & & & & $1(100 \%)$ \\
\hline Sarcoma & 1 & & & & & $1(100 \%)$ \\
\hline Dysgerminoma & 1 & & & & & $1(100 \%)$ \\
\hline Clear cell & 1 & & & & & $1(100 \%)$ \\
\hline
\end{tabular}

3 were highly expressed in TET1-overexpressing tumor. The levels of cell proliferation marker, phospho-histone H3, were shown to be decreased in TET1-overexpressing tumors (Figure 4E and 4F, and Supplementary Figure 1A-1C). Additionally, no significant difference in the expression of collagen IV between the analyzed tumor tissue samples was observed, indicating that TET1 may not be involved in tumor angiogenesis (Supplementary Figure 1D).

To analyze whether the endogenous TET1 expression is important for tumor growth, the expression of TET1 was inhibited using siRNA in ovarian cancer cells, and the control or TET1-knockdown cells were injected into the right and left flanks of nude mice, respectively. The obtained results demonstrated that the inhibition of TET1 expression in ovarian cancer cells induces tumor proliferation in vivo (Figure 5A). siTET1 tumor weights were shown to be two-fold higher than those of the tumors formed by injecting siNC cells. Furthermore, we confirmed that $5 \mathrm{hmC}$ levels were considerably decreased in siTET1 tumors (Figure 5B). We next examined cleaved caspase 3, pH2AX, and phospho-histone H3 levels, using immunofluorescence analysis, which showed that pH2AX levels were significantly decreased, while the levels of phospho-histone H3 were increased in siTET1 tumors, in comparison with those in the control samples.
No significant difference in cleaved caspase 3 levels was observed between siTET1 and siNC tumors (Figure $5 \mathrm{C}-5 \mathrm{~F}$ ), and collagen IV levels did not change between siTET1 and siNC tumors (Supplementary Figure 1E).

\section{TET1-dependent demethylation promotes transcriptional activation of $R A S S F 5$}

To understand how TET1 expression inhibits ovarian cancer growth, we performed a genome-wide RNA-seq analysis of total mRNA isolated from ES-2 cells treated with paclitaxel $(0.01 \mu \mathrm{g} / \mathrm{mL})$ (EVTAXOL) or without it (EV) for $24 \mathrm{~h}$ and from TET1-overexpressing ES-2 (ET) or empty vector-carrying (EV) cells (Figure $6 \mathrm{~A})$. We determined that the expression of 6762 genes was upregulated in EVTAXOL group, 455 genes were upregulated in the ET group, while 116 of these genes were upregulated in both groups (Figure 6B). Further analysis showed that the upregulated genes are involved in cell adhesion or cancer development, such as NF- $\kappa \mathrm{B}$ and TNF signaling pathways (Supplementary Figure 1F). In order to confirm these results, we verified the differential expression of several selected genes in ES-2 cells. CYP24, FOSB, PCDH10, THBS2, and RASSF5 were selected as representative genes for further analysis, as they are well-known regulators of cancer cell proliferation and 
A

(1)

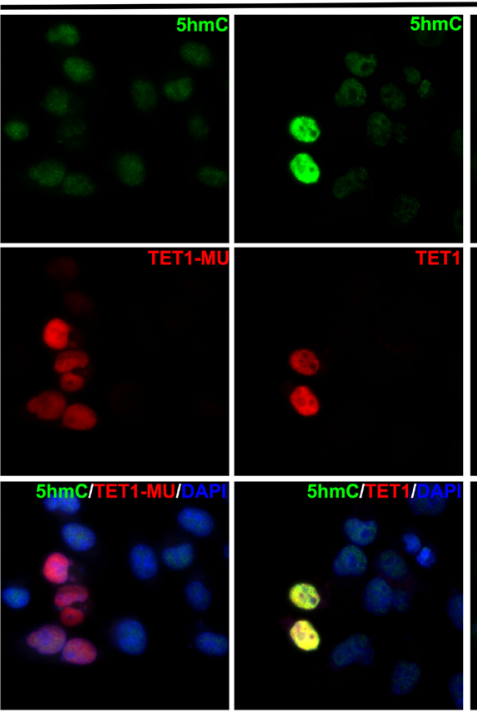

$\mathbf{E}$

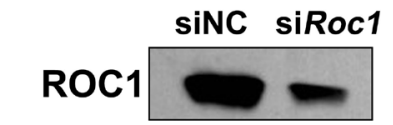

ERK1/2

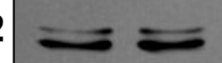

E

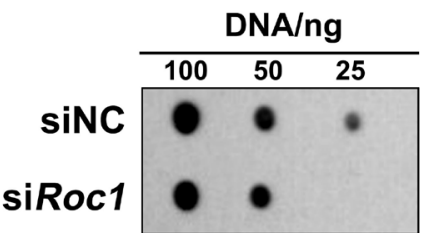

$\mathbf{G}$

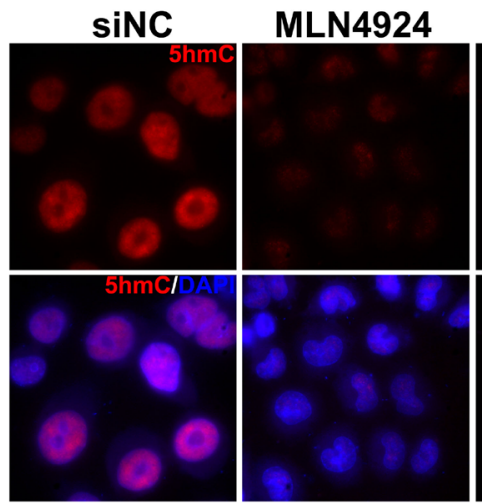

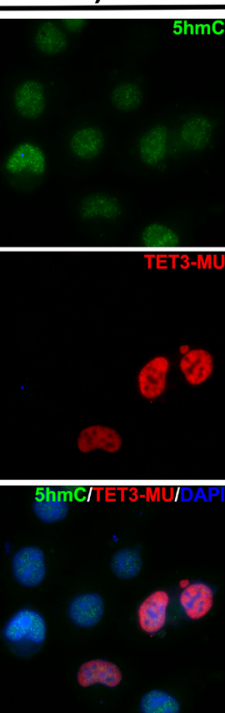
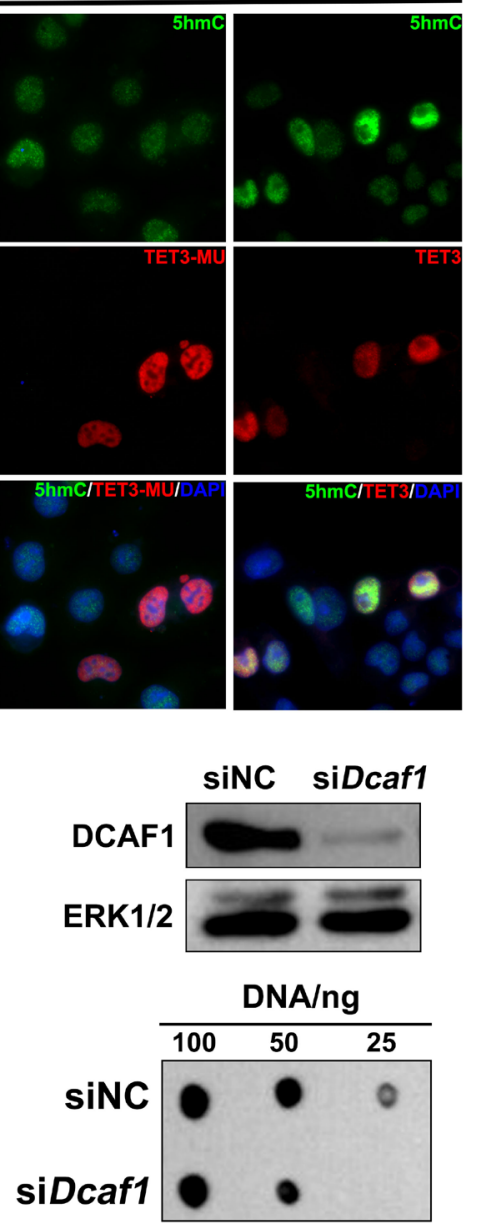

siRoc1
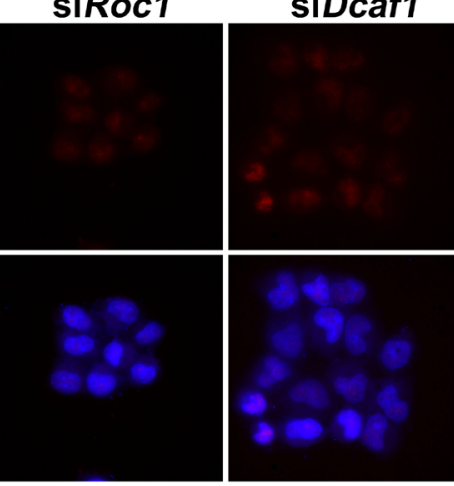

B
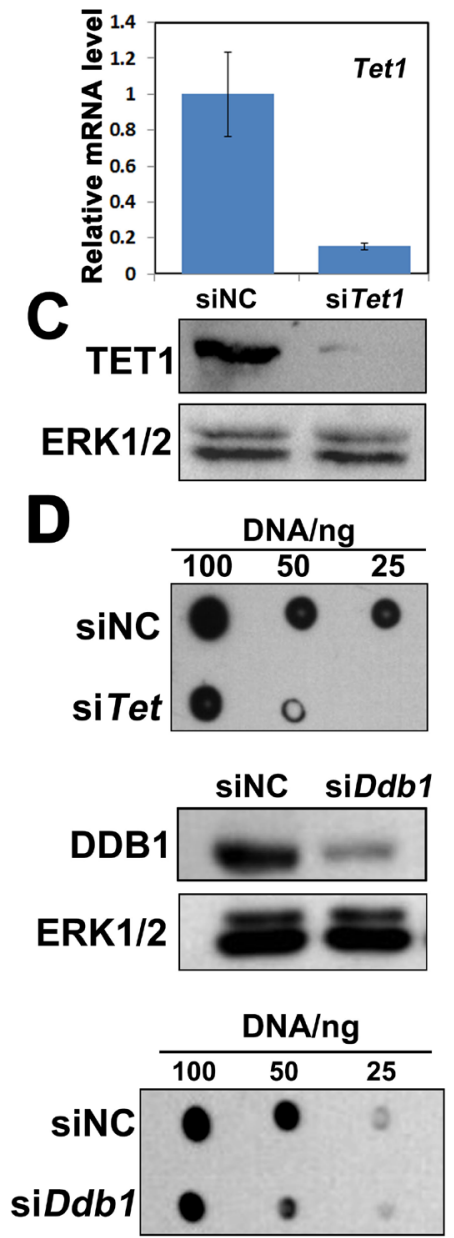

siDdb1

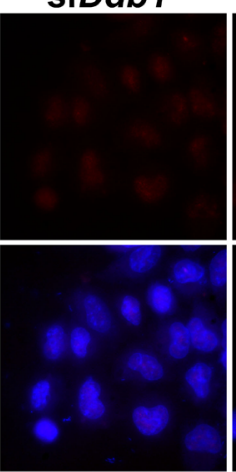

siTet1

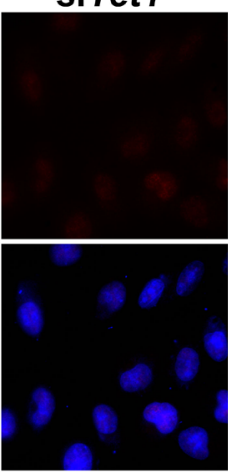

Figure 2: TET1 and CUL4-DDB1 ubiquitin E3 ligase complex depletion decrease $\mathbf{5 h m C}$ levels in ovarian cancer cells. (A) A2780 cells transfected with TET1, TET3, TET1 mutant (TET1-MU) and TET3 mutant (TET3-MU) plasmid were subjected to immunofluorescenceanalysis with antibodies to the indicated protein. Green, 5hmC; Red, Flag-labeled TET1 and TET3-overexpressing cells or TET1-MU and TET3-MU overexpressing cells; Blue, DAPI-stained DNA. (B) A2780 cells transfected with either siRNA negative control (siNC), or siTET1 were subjected to quantitative RT-PCR analysis of TET1 mRNA level. (C) A2780 cells transfected with either siRNA negative control (siNC), or siTET1 were subjected to immunoblot analysis with antibodies to TET1 proteins. (D) A2780 cells transfected with either siNC, or siTET1 were subjected to Dot-blot analysis of $5 \mathrm{hmC}$ levels. (E) A2780 cells transfected with siNC, siROCl, siDCAF1, or siDDB1 were subjected to immunoblot analysis with antibodies to the indicated protein. (F) A2780 cells transfected with siNC, siROC1, siDCAF1, or si $D D B 1$ were subjected to Dot-blot analysis with antibodies to the indicated protein. (G) Immunofluorescence results, showing that $R O C 1, D C A F 1, D D B 1$, and TET1 knockdown, and treatment with MLN4924 lead to the reduction of 5hmC levels in A2780 cells. Red, 5hmC; Blue, DAPI-stained DNA. A2780 cells transfected with siNC, siROC1, siDCAF1, siDDB1 or siTET1 and treatment with MLN4924 were subjected to immunofluorescence analysis with antibodies to the indicated protein. 
apoptosis, and the results obtained by qPCR analysis were shown to support our previously obtained results (Figure 6C).

RASSF is a family of tumor suppressors, which are frequently inactivated through promoter hypermethylation in various cancers [25-27]. To determine whether TET1 affects CpG methylation of RASSF5 promoter, we performed conventional bisulfite sequencing and showed that RASSF5 was $\sim 44.81 \%$ methylated in ES-2 control cells, whereas it was methylated $22.24 \%$ in TET1-overexpressing ES-2 cells (Figure 6D). No changes in $\mathrm{CpG}$ site methylation between the control and TET1-overexpressing ES-2 cells were observed when CYP24A1, FOSB, and PCDH10 promoters were analyzed (Supplementary Figure $1 G$ ). Additionally, to examine whether TET1 overexpression inhibits ovarian cancer growth by increasing RASSF5 levels, the effects of TET1 expression on RASSF5 levels were determined. Using immunofluorescence and western blot analyses, we confirmed that RASSF5 expression is upregulated in TET1-overexpressing cells, but not in TET1-MU overexpressing cells (Figure 6E and 6F).
Since TET1 overexpression was shown to promote the transcriptional activation of RASSF5, we hypothesized that TET1 silencing using the previously described siRNAs may lead to a decrease in RASSF5 expression. Following this, RASSF5 expression was shown to be downregulated in siTET1 cells (Figure 6G). Additionally, we observed a significant increase in RASSF5 levels in TET1-overexpressing tumor tissue samples (Figure 6H).

\section{TET1 inhibits ovarian cancer cells growth through an increase in RASSF5 expression}

To demonstrate that the observed decrease in the tumor cell proliferation rate was due to the TET1dependent activation of RASSF5, we performed RASSF5 knockdown experiments. RASSF5 mRNA and protein expression were shown to be efficiently suppressed in A2780 cells and TET1-overexpressing A2780 cells (Figure 7A and 7B). RASSF5 inhibition did not affect A2780 cells growth and colony forming ability by itself, but it was shown to partially rescue TET1-overexpression-induced cell death and colony formation defect (Figure $7 \mathrm{C}$ and
A

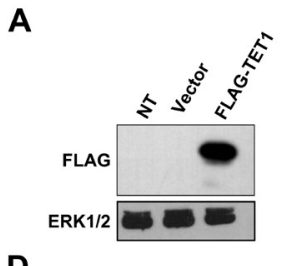

B

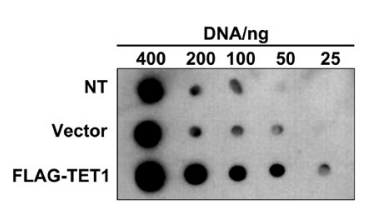

D
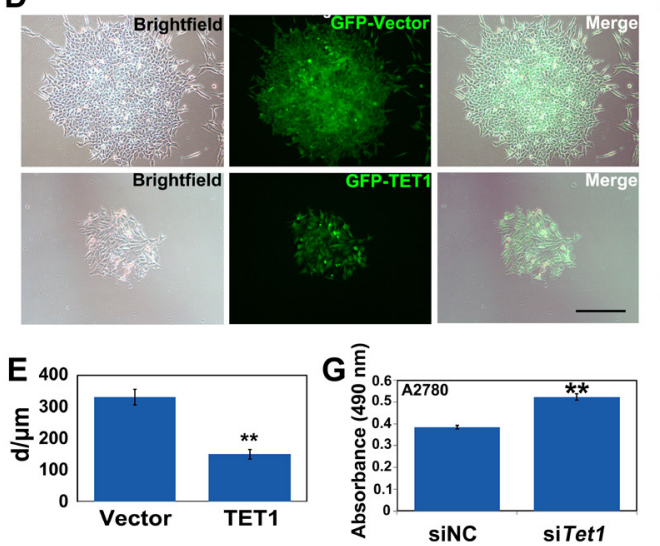

C

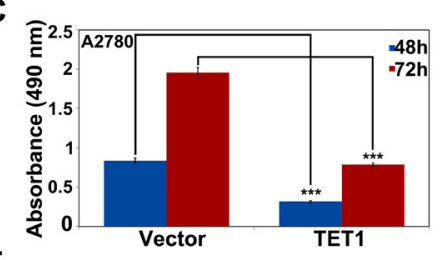

$\mathbf{F}$
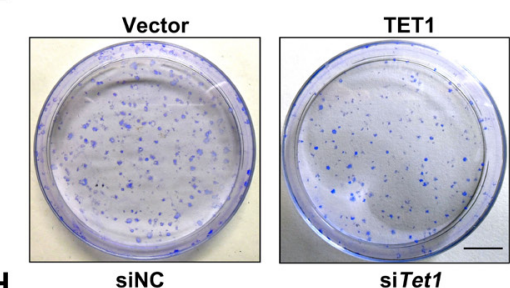

siTet1
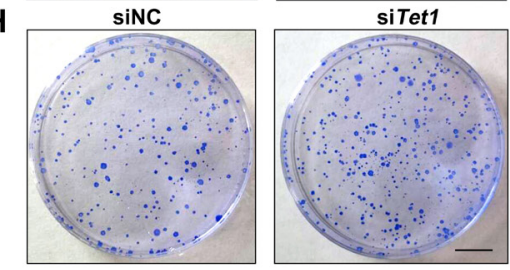
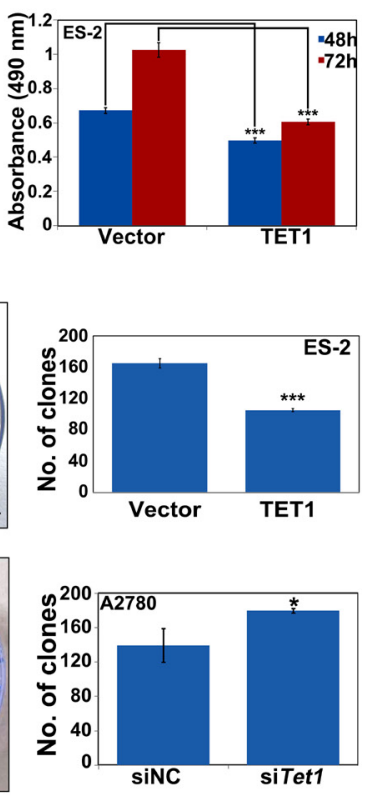

Figure 3: TET1 overexpression inhibits ovarian cancer cell proliferation and colony formation in vitro. (A) TET1overexpressing ES-2 cells and control cells were subjected to immunoblot analysis with antibodies to the indicated protein. No treatment cell (NT). (B) TET1-overexpressing ES-2 cells and control cells were subjected to Dot-blot analysis of 5hmC levels. (C) In vitro proliferation of TET1-overexpressing A2780 and ES-2 cells. $5 \times 10^{3}$ cells were plated in 96-well culture dishes in triplicate and followed by MTT assay. Data are means $\pm \mathrm{SE}$ of triplicate cultures from a representative experiment. (D) Abundant GFP signals were observed using fluorescence microscope. Left panel: bright field image. Middle panel: dark field image. Right panel: merge. Scale bar, $50 \mu \mathrm{m}$. (E) Quantitative analysis of the results presented in D. (F) Colony formation of ES-2 cells, with or without TET1 overexpression. Colony numbers and colony diameter were counted at day 10. Scale bar, $50 \mu \mathrm{m}$. Data are means \pm SE of triplicate cultures from a representative experiment. (G) In vitro proliferation of TET1-knockdown A2780 cells. siNC and siTET1 cells were plated in 96-well culture dishes in triplicate and followed by MTT assay. Data are means \pm SE of triplicate cultures from a representative experiment. (H) Colony forming of siTET1-A2780 cells. Results are represented as mean values \pm SEs obtained in three independent experiments. Scale bar, $50 \mu \mathrm{m} .{ }^{* * *} p<0.001 ; * * p<0.01 ; *$ $p<0.05$. 
7D). In TET1-overexpressing cells, RASSF5 inhibition led to a decrease in $\mathrm{pH} 2 \mathrm{AX}$ levels (Figure 7E).

\section{DISCUSSION}

Epithelial ovarian cancer is a heterogeneous disease, comprising many subtypes with distinct clinicopathological and molecular features, and according to these characteristics, they are classified into four major histologic subtypes: serous adenocarcinoma (SAC), mucinous adenocarcinoma (MAC), endometrioid adenocarcinoma (EAC), and clear cell carcinoma (CCC). Although previous studies showed that different histologic subtypes of ovarian cancer have different underlying genetic traits, such as $p 53$ mutations in SAC, $P T E N$ mutations in EAC, and KRAS mutations in MAC [28], their epigenetic features have remained elusive. Epigenetic alterations have long been linked to ovarian cancer initiation and progression, including changes in DNA methylation and histone modifications. The best characterized epigenetic marker is DNA methylation/ demethylation. In addition to DNMT functions, TET proteins have recently been identified as the novel regulators of DNA methylation. With the increasing number of studies investigating epigenetic alterations and tumorigenesis, TETs and TET-mediated DNA demethylation were shown to play important roles in tumor development and progression [29].

Here, we demonstrated that TET1 effect the methylation of DNA in human ovarian cancer tissues and cells, and that the expression of TET1 and 5hmC levels were significantly decreased in ovarian cancer tissue and cells, in comparison with those in the normal, healthy tissue. Furthermore, we showed that TET1 overexpression leads to an increase in $5 \mathrm{hmC}$ levels and inhibits cell proliferation and colony formation in several ovarian cancer cell lines, while TET1 silencing induced the opposite effects in vitro and in vivo. Our gain- and lossof-function studies demonstrated that TET1 expression inhibits ovarian tumor growth and promotes apoptosis in
A

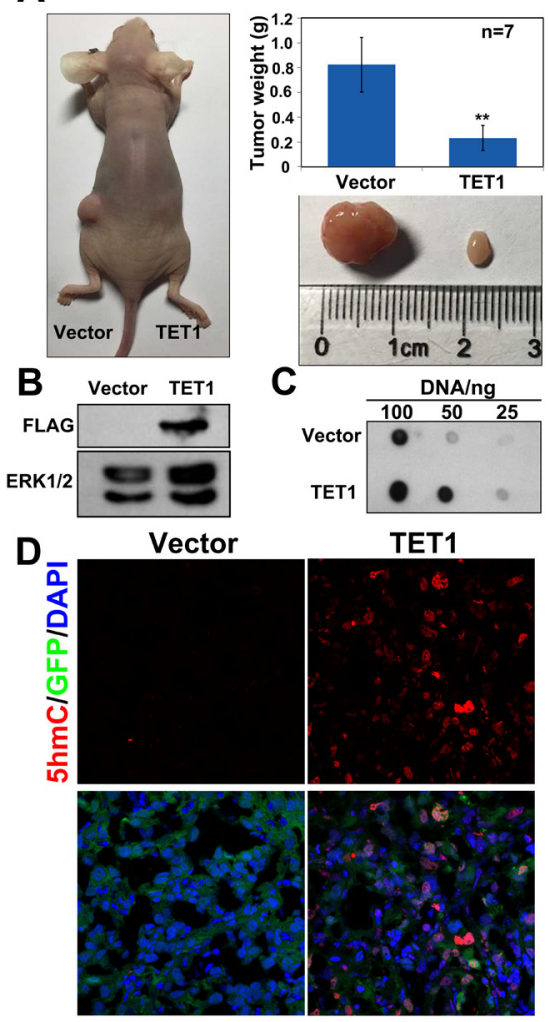

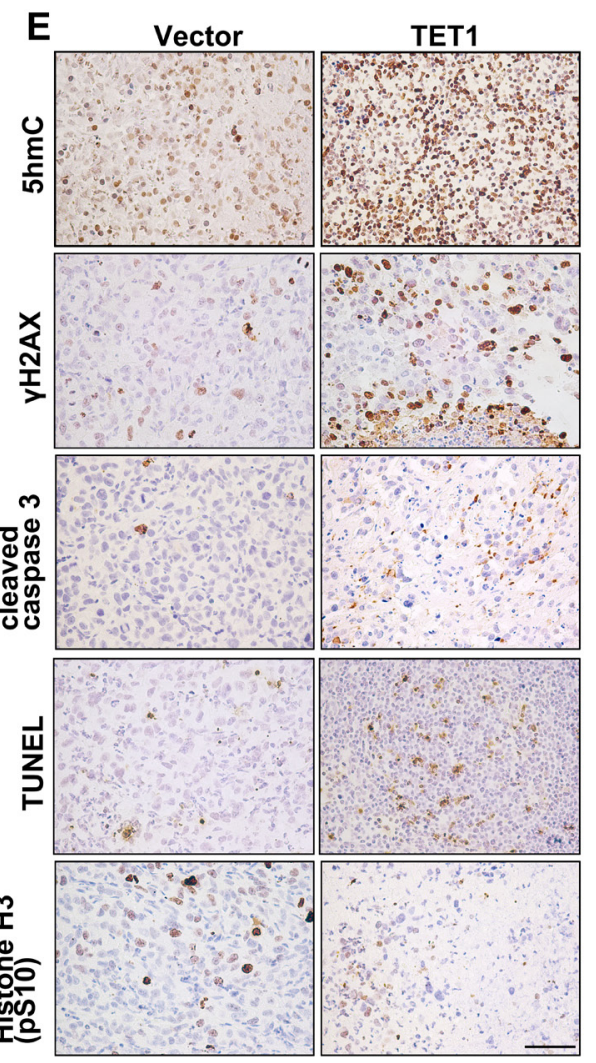

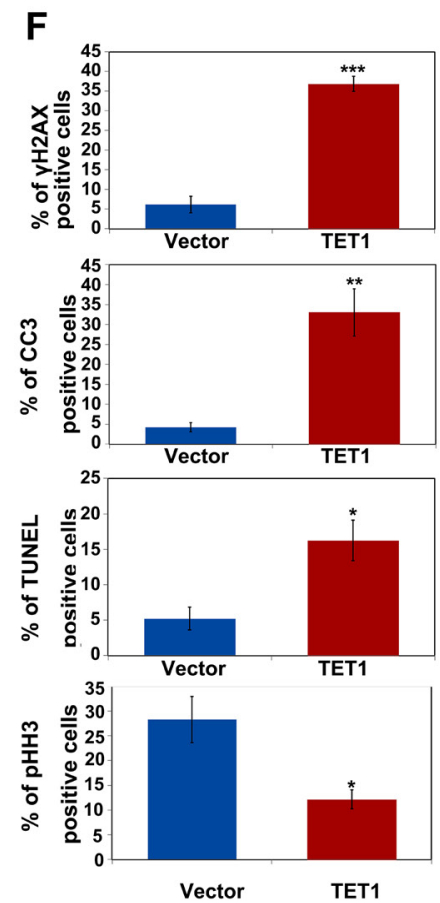

Figure 4: TET1 overexpression in tumors inhibits tumor growth in vivo. (A) Equal numbers of ES-2 infected with LV-CON or LV-GFP-TET1-Flag were implanted subcutaneously into the left and right flanks of nude mice, respectively. Tumors were removed and weighed after 30 days. $n=7$ tumors for each group. Results are represented as mean values \pm SEs obtained in seven independent experiments. (B) Flag-tagged protein expression in tumor tissues that developed from the implanted ES-2 cells. (C) The levels of 5hmC in tumor tissues that developed from the implanted ES-2 cells. (D) Levels of 5hmC and TET1 in cryosections prepared from ES-2 cell-derived tumor tissues. Red, 5hmC. Green, TET1. Blue, DAPI staining. (E) IHC analysis of 5hmC, $\gamma \mathrm{H} 2 \mathrm{AX}$, cleaved caspase 3, and phosphohistone H3 levels, and TUNEL staining of ES-2-derived tumor tissue samples. Scale bar, $50 \mu \mathrm{m}$. (F) Quantitative of percentage of the positive cell in (E) was performed in three randomly chosen fields for each group. 
vivo, while TET1 inhibition in tumor cells promotes tumor growth in vivo.

CUL4-DDB1 ubiquitin E3 ligase complexes represent the largest family of E3 ligases and require cullin neddylation for their activation. In our previous study, we determined that CUL4-DDB1 complex regulates mammalian oocyte $5 \mathrm{hmC}$ levels by activating TET [30]. We hypothesized that CUL4-DDB1 ubiquitin E3 ligase complexes activates TET, which convert $5 \mathrm{mC}$ to $5 \mathrm{hmC}$, and increase DNA demethylation levels in ovarian cancer cells. The results of our studies confirmed that CUL4DDB1 ubiquitin E3 ligase complexes increase $5 \mathrm{hmC}$ production in these cells by acting upstream of TET1, most likely activating it, and determined that the inhibition of CUL4-DDB1 ubiquitin E3 ligase complex expression can lead to a decrease in $5 \mathrm{hmC}$ levels. Therefore, results previously obtained by us and other groups indicate that CUL4-DDB1 ubiquitin E3 ligase complexes may affect ovarian cancer cell proliferation and apoptosis, not only by leading to the accumulation of its substrate, DNA replication licensing factor, but through the regulation of epigenetic alterations as well. Neri et al. [31] reported that $5 \mathrm{hmC}$ levels are considerably reduced in several types of human cancer, such as colon, breast, and prostate cancers. The data obtained in this study demonstrate that $5 \mathrm{hmC}$ levels are considerably decreased in ovarian cancer tissue samples and cells. The levels of $5 \mathrm{hmc}$ were different in four major histologic subtypes, and the lowest levels were detected in CCC samples. Therefore, we selected ES-2 cell line, derived from a CCC, for TET1-overexpression experiments, and demonstrated that this leads to an increase in $5 \mathrm{hmC}$ levels and the inhibition of ovarian cancer growth in vivo and in vitro. Additionally, this indicates that TET1 activity and 5hmC levels play important roles in ovarian cancer development and progression, and that $5 \mathrm{hmC}$ levels may represent a valuable biomarker for the diagnosis of ovarian cancer.
A

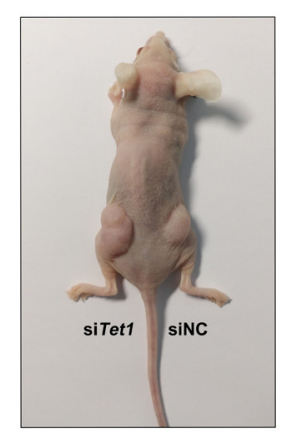

C

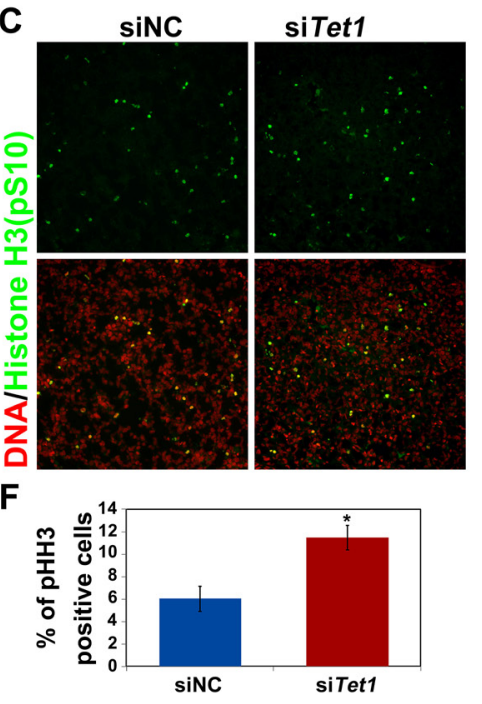

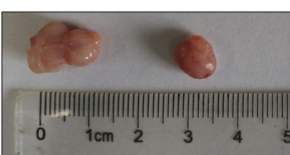
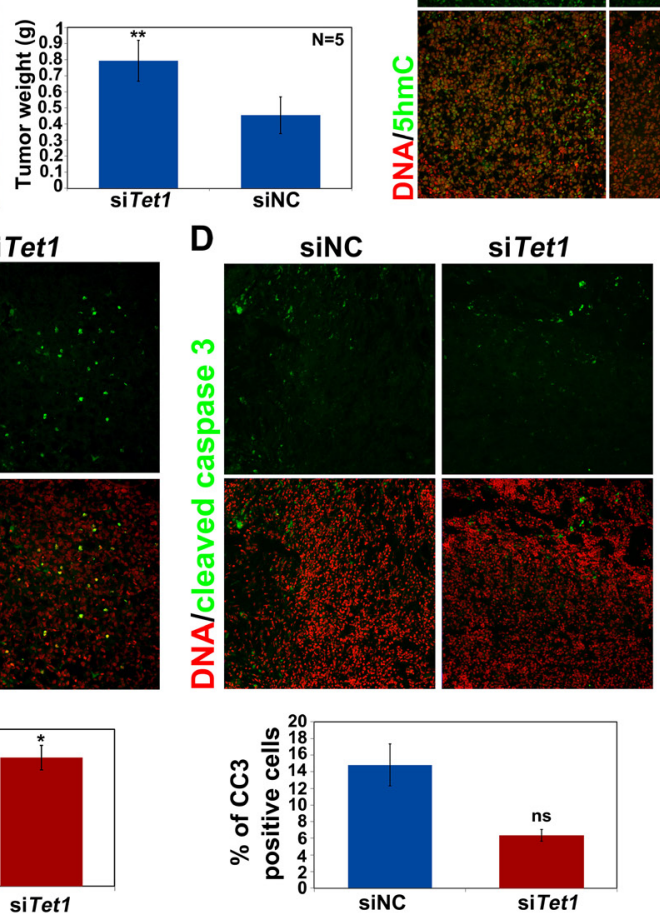

B $\quad$ siNC $\quad$ siTet1

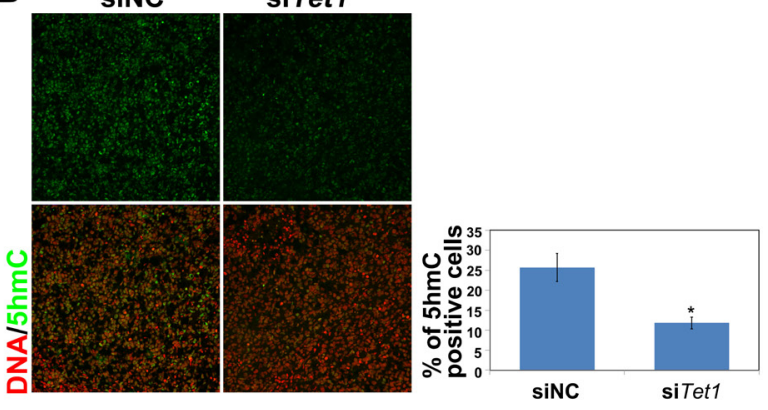

E

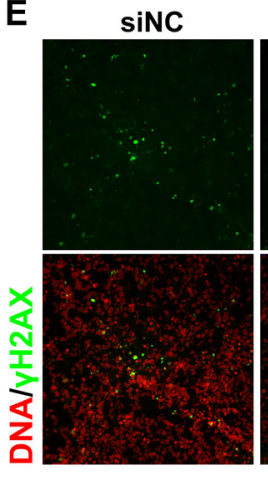

siTet1
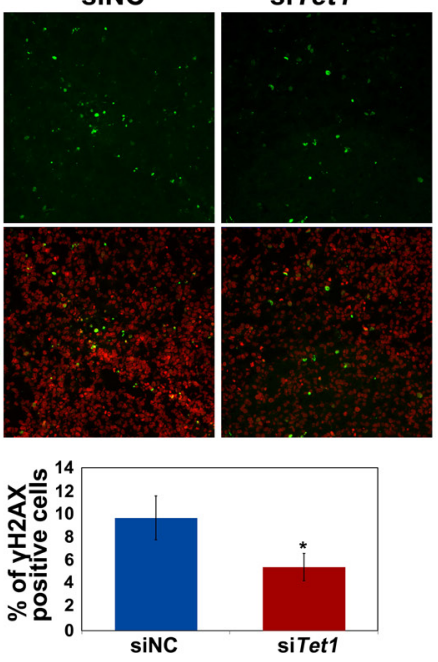

Figure 5: TET1 gene silencing in tumors promotes tumor growth in vivo. (A) A2780 cells, transfected with either siNC or siTET1, were injected subcutaneously into the right and left flanks of nude mice, respectively, and the resulting tumor tissue was removed and weighed $(\mathrm{n}=5)$. Results are represented as mean values \pm SEs obtained in five independent experiments. (B) Immunofluorescence analysis of $5 \mathrm{hmC}$ levels (green) in tumor tissues with or without TET1 expression. Quantitative of percentage of the positive cell in B was performed in three randomly chosen fields for each group. (C-E) Immunofluorescence analysis of phospho-histone H3, cleaved caspase 3 (CC3), and $\gamma \mathrm{H} 2 \mathrm{AX}$ levels in tumor tissues, with or without TET1 expression. (F) Quantitative of percentage of the positive cell in (C-E) was performed in three randomly chosen fields for each group. ns, not significant. 
Zelic et al. [32] showed that the hypermethylation in the promoter regions of tumor suppressor genes is usually observed in cancer, but global DNA hypomethylation can be observed in cancer tissues as well. Promoter regions of some genes were shown to be methylated in epithelial ovarian cancers, such as Fanconi anemia complementation group $\mathrm{F}$ (FANCF) and RASSF $2 A$ genes [33, 34]. RASSF5/ NORE1 is an important tumor suppressor, which can inhibit tumor growth by promoting G1/S arrest [35, 36]. Additionally, this molecule is a RAS-proapoptotic factor, which can induce apoptosis by activating p53 pathway [37]. However, RASSF5 is frequently silenced in human cancers through promoter methylation, and the induction of RASSF5 expression was shown to inhibit cancer cell growth in humans [38]. Here, we showed that the expression of RASSF5 is significantly increased in TET1-overexpressing cells, in comparison with that in the controls, and that the methylation levels of RASSF5 promoter region are increased in ovarian cancer cells, which agrees with the results obtained in the previous studies. TET1 overexpression was shown to increase RASSF5 promoter demethylation, which further stimulates
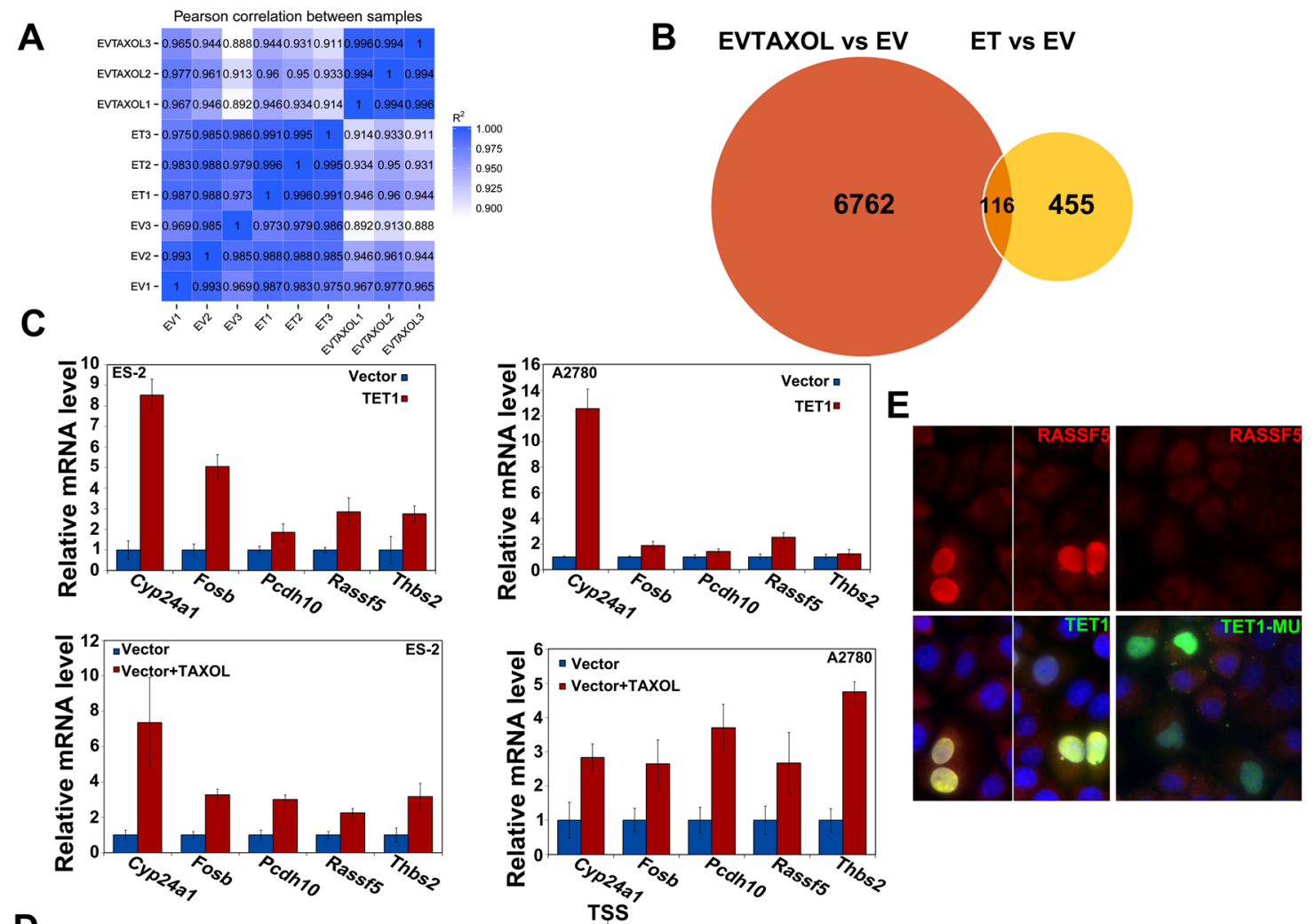

Dector
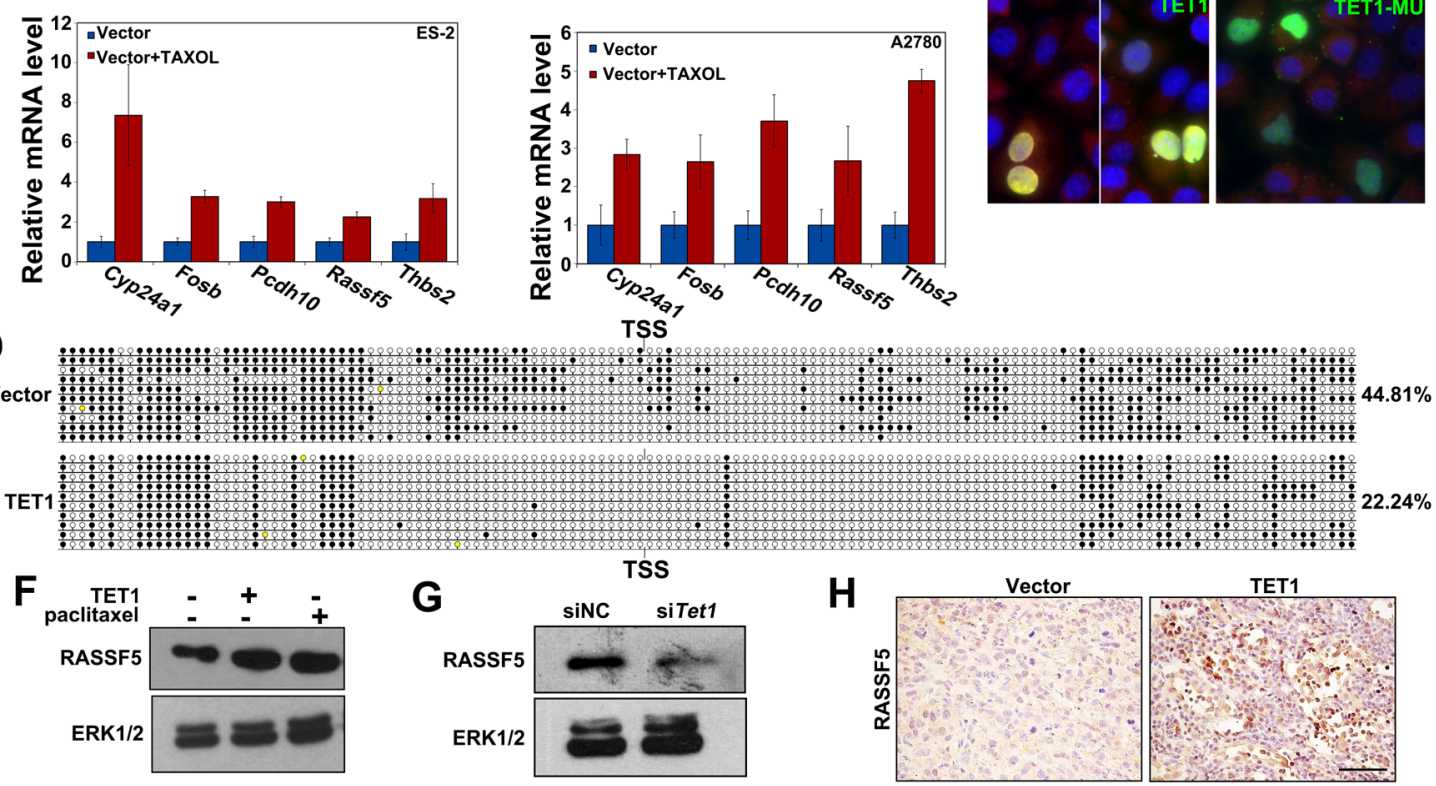

Figure 6: $R A S S F 5$ is upregulated in TET1-overexperessing ovarian cancer cells and tumors. (A) Genome-wide RNA-seq analysis of gene expression levels in EVTAXOL, ET, and EV cells. (B) Upregulated genes in EVTAXOL and ET groups, in comparison with those in the EV group. (C) qRT-PCR confirm up-regulated gene in EVTAXOL and ET groups. (D) TET1 overexpression decrease RASSF5 promoter methylation in ovarian cancer cells. Open and filled circles represent unmethylated and methylated CpG islands, respectively. The percentages of methylated CpGs are indicated. (E) Immunofluorescence analysis of RASSF5 (red) levels in ovarian cancer cells. Green, Flag-labeled TET1 and TET1-MU overexpressing cells. Blue, DAPI staining. (F, G) Western blot results, showing RASSF5 levels in TET1-overexpressing, paclitaxel-treated, and siTET1-treated cells. (H) IHC staining, showing RASSF5 levels in TET1-overexpressing tumor tissue samples. 
RASSF5 expression, leading to the suppression of ovarian cancer cell proliferation and colony formation. This indicates that RASSF5 gene may represent a direct TET1 target, although it is not completely clear whether TET1 directly interacts with $R A S S F 5$, or through the interaction with other bridge proteins. Further analyses confirmed that RASSF 5 expression increases in TET1-overexpressing ovarian cancer cells, but the obtained results suggested that other TET1 downstream targets may also mediate the effects of this molecule on ovarian cancer cell proliferation and colony forming ability. Another possibility is that $5 \mathrm{hmC}$ provides a platform for the recruitment of TET1 to specific chromatin regions. Further delineation of the mechanistic link between TET1, RASSF5, and 5hmC production should allow a better understanding of TET1 functions in ovarian cancer cells.

Our results for TET1 expression in ovarian cancer cell have clinical and therapeutic implications. 1) Several reports have found a correlation between reduce $5 \mathrm{hmC}$ and poor patient prognosis in various cancers, such as malignant glioma and colorectal cancer [39, 40]. We also have observed TET and $5 \mathrm{hmC}$ protein levels were dramatically decreased in ovarian surface epithelial cancer tissues. These results indicate that TET1 downregulation might be a key step initiating ovarian cancer and could possibly be used as an early diagnostic marker for ovarian cancers. 2)In our study, we also confirmed that TET1 overexpression increase chemosensitizing effects of paclitaxel and cis-platinum, which are firstline anticancer agents for human ovarian cancer (date not shown). In addition, TET1 overexpression activated DNA damage responses and apoptosis pathway with paclitaxel treatment, as shown by accumulations of $\mathrm{pH} 2 \mathrm{AX}$ (Figure 7E) and cleaved caspase-3 (data not shown). These results show that TET1 overexpression sensitize ovarain cancer cell to chemotherapeutic drug treatment. Thus, small molecules that can increase TET1 activity may have the therapeutic potential to enhance the effect of chemotherapy for ovarian cancer patients.

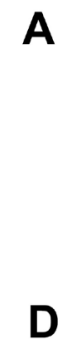

A
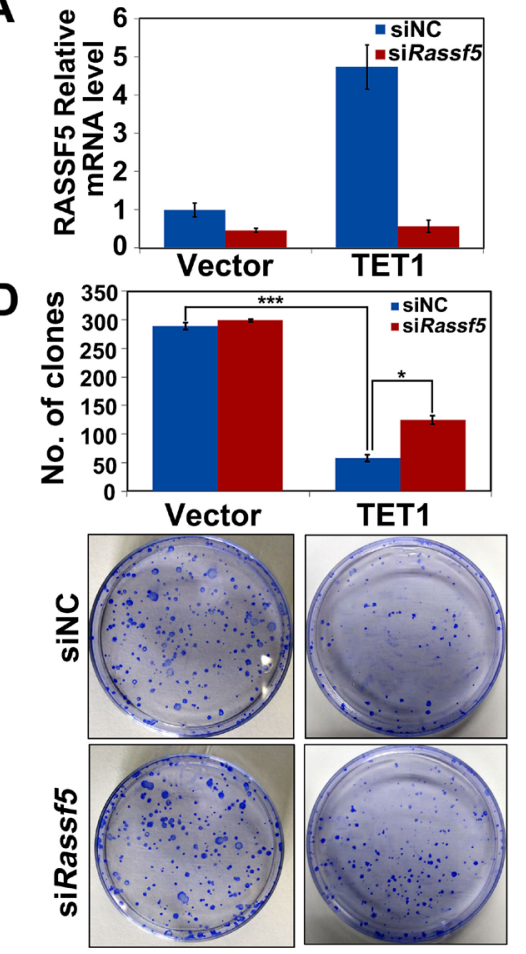
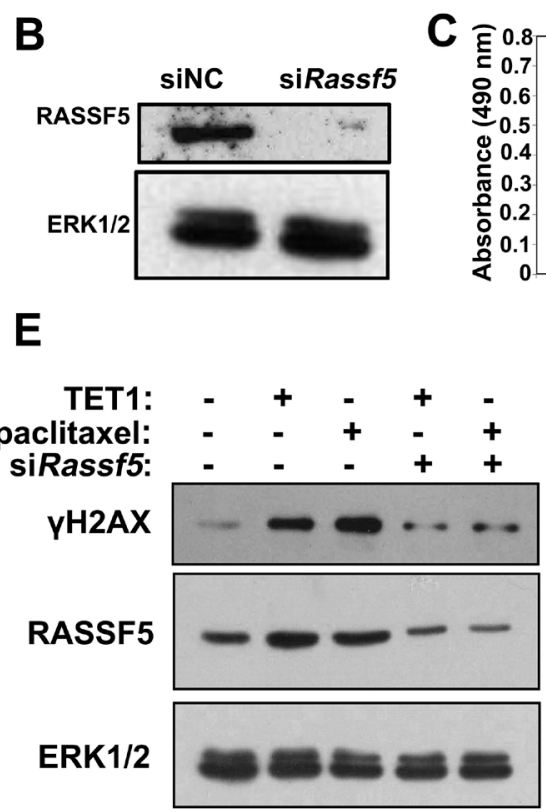

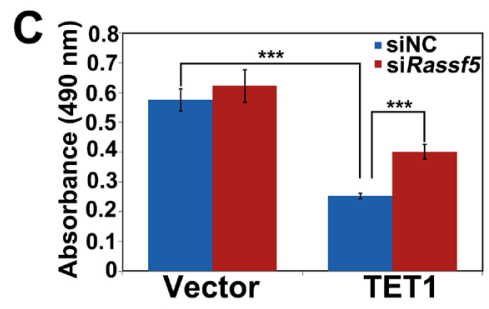

$\mathbf{F}$

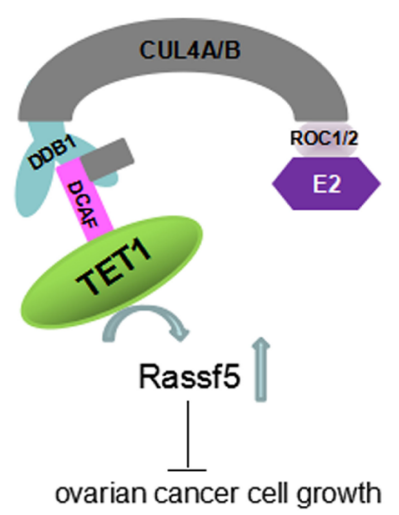

Figure 7: Inhibition of $R A S S F 5$ expression rescues TET1-overexpression-induced phenotype of ovarian cancer cells. (A) A2780 cells stably expressing control vector and TET1 were transfected with siNT and siRASSF5. qPCR detect RASSF5 mRNA expression. Three replicates are included in this experiment. The error bars represent SEs. (B) A2780 cells stably expressing control vector and TET1 were transfected with siNT and siRASSF5. Immunoblot analysis was performed with the indicated antibodies. (C) Proliferation of TET1-overexpressing or control A2780 cells after RASSF5 silencing. Data are means \pm SE of triplicate cultures from a representative experiment. $* * * p<0.001$. (D) Colony forming assay was performed and the colonies were stained with crystal violet for quantification. Data are means $\pm \mathrm{SE}$ of triplicate cultures from a representative experiment. ${ }^{* * *} p<0.001 ; * p<0.05$. (E) RNAi depletion of $R A S S F 5$ rescued the $\gamma \mathrm{H} 2 \mathrm{AX}$ levels following TET1-overexpression. A2780 cells stably expressing control vector and TET1 were transfected with siNT and siRASSF5. Immunoblot analysis was performed with the indicated antibodies. (F) Schematic diagram showing TET1 functions in ovarian cancer cells. In ovarian cancer cells, CUL4-DDB1 ubiquitin E3 ligase complex activates TET1, regulate RASSF5 DNA methylation levels and maintain the expressions of RASSF5 for ovarian cancer cell growth. 


\section{MATERIALS AND METHODS}

\section{Plasmids and cell lines}

Expression constructs encoding for TET1 or TET3 $\mathrm{C}$-terminal cysteine-rich dioxygenase (CD) domain (FlagTET1 or Flag-TET3) and activity-dead mutant TET1 (TET1-MU) or TET3 (TET3-MU) were kindly provided by Dr. Heng-yu Fan.

Human ovarian cancer cell lines, SKOV3, A2780, ES-2, HO8910, OV2008, C13, 293T, and Hep3132 were purchased from ATCC. The immortalized mouse ovarian surface epithelium (mOSE) were reported previously [41]. All cell lines were cultured under an atmosphere of $5 \% \mathrm{CO}_{2}$ at $37^{\circ} \mathrm{C}$. All cells were cultured in Dulbecco's Modified Eagle Media( DMED, Gibco) supplemented with $10 \%$ fetal bovine serum (FBS; Gibco) and 1\% penicillinstreptomycin solution (Gibco). The chemotherapeutic drugs used in this study included paclitaxel $(0.01 \mu \mathrm{g} / \mathrm{mL})$ (Bristol-Myers Squibb, New York, NY, USA). MLN4924 (MedChemExpress) was applied in the concentration of 1 $\mu \mathrm{M}$. All reagents were used according to the instructions provided by the suppliers.

\section{TET1-overexpressing ovarian cancer cell lines}

ES-2 and A2780 were infected by lentiviruses carrying empty vectors (LV-CON) or green fluorescent protein (GFP)-TET1-Flag (LV-TET1). Briefly, 293T Phoenix retrovirus packaging cells were transfected with empty vectors and GFP-TET1-Flag expressing plasmids. Forty-eight hours after the transfection, retroviral supernatant was supplemented with $5 \mu \mathrm{g} / \mathrm{mL}$ polybrene, filtered through a $0.45-\mu \mathrm{m}$ filter, and used for infection. Ovarian cancer cells were seeded in $60-\mathrm{mm}$ dishes and infected with lentivirus carrying TET1 or control vector, and $48 \mathrm{~h}$ later, they were selected with $5 \mu \mathrm{g} / \mathrm{mL}$ puromycin in the culture medium.

\section{Colony formation assay}

Ovarian cancer cells (500 cells/dish) were seeded in 60-mm dishes for approximately 10 days and the culture medium was replaced with fresh medium every 3 days. All experiments were performed in triplicates, and plates were incubated in a $5 \% \mathrm{CO}_{2}$ humidified atmosphere at $37^{\circ} \mathrm{C}$. Colonies were stained using Coomassie Brilliant Blue and counted 10 days after plating.

\section{RNA interference}

Ovarian cancer cells were transfected with different siRNAs using Lipofectamine RNAiMAX Reagent (ThermoFisher Scientific). Briefly, cells were seeded in six-well plates and transfected with siRNA and Lipofectamine RNAiMAX Reagent, each incubated separately in Opti-MEM for $5 \mathrm{~min}$, mixed together for
$10 \mathrm{~min}$ at room temperature, and then the mixture was applied to the cells plated in $1 \mathrm{~mL}$ of medium (final siRNA concentration, $80 \mathrm{nM})$. The siRNA sequences used in this experiment (GenePharma, Shanghai, China) were as follows:

siCON(siNC): UUCUCCGAACGUGUCACGUTT. siTET1: CAGGUGGGUUUGCAGAAACAA. SIROC1: GACUUUCCCUGCUGUUACCUAATT. siDCAF1: UCACAGAGUAUCUUAGAGATT. siDDB1: GGCCAAGAACAUCAGUGUGTT.

\section{Cell growth assay}

Cells were seeded in 96-well plates at a density of $5 \times 10^{3}$ cells/well in DMEM containing $10 \%$ FBS. After they had adhered, cell growth was monitored for 48 or 72 $\mathrm{h}$, and then assessed using MTT assay. Briefly, $20 \mu \mathrm{L}$ of MTT solution ( $5 \mathrm{mg} / \mathrm{mL}$ in PBS) was added into triplicate wells and cells were incubated for 4-6 h in an incubator. Absorbance at $490 \mathrm{~nm}$ was determined using a microplate reader.

\section{Mice and xenograft models}

Mice $(n=15)$ were housed under standard conditions, under a $14 \mathrm{~h} / 10 \mathrm{~h} \mathrm{light/dark}$ schedule, and they were provided food and water ad libitum. All animal protocols were in accordance with the NIH Guide for the Care and Use of Laboratory Animals. To assess cancer cell proliferation in vivo, ovarian cancer cells $\left(1 \times 10^{6}\right)$ were subcutaneously transplanted into both back flanks of 8-week-old female nude mice. Four weeks later, primary tumor masses were excised and fixed overnight in $10 \%$ PBS-buffered formalin, dehydrated using an ascending series of graded ethanol solutions, and then embedded in paraffin.

\section{Immunohistochemical (IHC) analysis}

Paraffin-embedded human tissues from ovarian tumors were provided by the Jiaxing Maternity and Child Health Care Hospital, China. Paraffin-embedded human ovarian cancer tissue microarrays (TMAs) were purchased from Fanpu Biochec, Inc. Each patient specimen in these TMAs was represented in two cores on the slide, each measuring $1.5 \mathrm{~mm}$ in diameter. Clinical information was provided by the commercial source. The use of archived cancer samples for this study was approved by the Jiaxing University Institutional Review Board.

Primary tumor masses were cut into 5- $\mu \mathrm{m}$ tick sections with a Leica RM2235 microtome and stained with hematoxylin and eosin (H\&E). For immunochemistry, sections were deparaffinized and rehydrated with xylene and an alcohol gradient. Afterwards, the sections were incubated in $0.3 \% \mathrm{H}_{2} \mathrm{O}_{2}$. After the antigens were retrieved using $10 \mathrm{mM}$ sodium citrate $(\mathrm{pH} 6.0)$, the sections were incubated with anti-5hmC (Active Motif), anti-ROC1, 
anti-DDB1 (Epitomic), anti-DCAF1 (ProteinTech), anti-pH2AX, anti-cleaved caspase 3 (Cell Signaling Technology), and anti-phospho-histone H3 (Epitomics) antibodies (1:200) using a Vector ABC kit (Vector Laboratories), at room temperature for $1 \mathrm{~h}$, which was followed by a reaction with biotin-labeled goat secondary antibodies for $30 \mathrm{~min}$. Staining was performed using Vectastain $\mathrm{ABC}$ kits and 3,3'-diaminobenzidine (DAB) peroxidase substrate kits (Vector Laboratories, Burlingame, CA, USA). Staining intensity of $5 \mathrm{hmC}$, ROC1, DDB1, DCAF1, pH2AX, cleaved caspase 3, and phospho-histone $\mathrm{H} 3$ was scored by a pathologist (L. Guo).

\section{TUNEL assay}

Terminal deoxynucleotidyl transferase-mediated dUTP nick-end labeling (TUNEL) assays were performed with $10 \%$ formalin-fixed paraffin-embedded sections, using an Apop Tag Plus Peroxidase In Situ Apoptosis Detection Kit (Serologicals Corporation, Norcross, GA, USA), according to the manufacturer's instructions.

\section{Immunofluorescence analysis}

Cultured cells were seeded on cover slips and transfected with siCON, siTET1, or GFP-TET1-Flag plasmids. After $24 \mathrm{~h}$, cells were washed with PBS, and fixed for $10 \mathrm{~min}$ at room temperature with $4 \%$ paraformaldehyde in PBS.

Primary tumor masses were fixed in $4 \%$ paraformaldehyde, embedded in O.C.T. compound (Sakura Finetek USA, Inc.), and stored at $-80^{\circ} \mathrm{C}$ before preparing $7-\mu \mathrm{m}$ sections using a Leica CM1950 cryomicrotome (Leica Microsystems, Wetzlar, Germany).

Cells and sections were permeabilized with $0.3 \%$ Triton X-100 in PBS, incubated with the blocking buffer (PBST containing $5 \%$ bovine serum albumin (BSA)), and were sequentially probed with anti-5hmC (Active Motif), anti-pH2AX, anti-cleaved caspase 3 (Cell Signaling Technology), and anti-phospho-histone H3 (Epitomics) antibodies $(1: 200)$, which was followed by a reaction with Alexa Fluor 594- or 488-conjugated secondary antibodies (Molecular Probes). Slides were mounted using VectaShield and stained with 4', 6-diamidino-2phenylindole (DAPI, Vector Laboratories). Digital images were acquired using an epifluorescence microscope (Nikon Eclipse 80i) at 4-100× magnification.

For $5 \mathrm{hmC}$ staining, cultured cells were fixed in PBS-buffered 4\% paraformaldehyde for $30 \mathrm{~min}$, and then treated with $4 \mathrm{~N} \mathrm{HCl}$ for 15 min at room temperature, in order to denature double-stranded DNA. The samples were extensively washed with PBS and then blocked with 5\% BSA in PBS for $1 \mathrm{~h}$. Subsequently, samples were incubated with anti-5hmC primary antibody (1:400) at room temperature for $1 \mathrm{~h}$. Alexa Fluor 594- or 488-conjugated secondary antibodies were used to detect the signals. The samples were mounted and images were acquired as described above.

\section{Western blot analysis}

Total proteins were isolated from the cell extracts, and $30 \mu \mathrm{g}$ of protein were separated by SDS-PAGE and transferred to polyvinylidene difluoride (PVDF) membranes (Millipore, Bedford, MA, USA). After probing with primary antibodies, membranes were washed in Trisbuffered saline that contained $0.05 \%$ Tween-20 (TBST) and incubated with a horse-radish peroxidase-linked secondary antibody. Finally, the obtained bands were detected using an Enhanced Chemiluminescence Detection Kit (Amersham). The primary antibodies used were as follows: anti-FLAG (Sigma-Aldrich), anti-p-H2AX (Ser139) (Cell Signaling Technology), anti-ROC1 (Epitomics), anti-DDB1 (Epitomics), anti-DCAF1 (ProteinTech), antiRASSF5 (Abcam), anti-TET1 (Abcam) and anti-ERK1/2 (Santa Cruz Biotechnology) antibodies (1:1000).

\section{RNA extraction and real-time RT-PCR analysis}

Total RNA was extracted using Trizol (Invitrogen), according to the manufacturer's instructions. Real-time PCR analysis was performed using Q Tag SYBR Green Master Mix (Becton Dickinson Medical Devices, USA) and an Applied Biosystems 7500 Real-Time PCR System. Relative mRNA levels were determined by normalizing the obtained expression levels to the endogenous $\beta$-actin mRNA levels, using Microsoft EXCEL. For each of the indicated genes, the relative transcript levels of the control sample were set at 1 , and the transcript levels of other samples were compared with that of the control. Quantitative RT-PCR reactions were performed in triplicates. The following primers were used to amplify target genes:

p-actin: $\quad$ 5'-GCTCTTTTCCAGCCTTCCTT-3'; 5'-GTACTTGCGCTCAGGAGGAG-3'.

TET1: 5'-AAGTGAAACCGAACCCCATT-3';

5'-ACTGAGTCTTCCCGAAGGCAT-3'. CYP24A1: 5'-CAGAGCTTCAACTGCATTTGG-3';

5'-TGTAGAATGCCTTGGATCCC-3'.

FOSB: 5'-GAAAGCCTTTCCTCGGTCTC-3';

5'-TTCCTGGAGAGGATGTGAGG-3'. PCDH 10: 5'-AGAATTACTGCTATCAGGTATGC

CT-3'; 5'-TCGTTGGACAAAATGCTTCC-3'.

RASSF5: 5'-CACTGCGACTCTGGGATCTC-3';

5'-TCACTTCCTGGCAGGAGAAG-3'.

THBS2: 5'-TTCTGTTTCTGTGTTGTGGGG-3'; 5'-AGTGCAGGGTTTCAGTGGTG-3'.

\section{Bisulfite sequencing}

DNA methylation profile was analyzed using bisulfite sequencing, with EpiTect Plus DNA Bisulfite Kit, according to the manufacturer's instructions. 
Table 2: Primers used to amplify gene targets

\begin{tabular}{|c|c|}
\hline Gene name & Sequence $\left(5^{\prime}-3^{\prime}\right)$ \\
\hline \multirow[t]{4}{*}{ CYP24A1 } & Forward (F)1: AGTTTAGGTTGGGGGTATTTGG \\
\hline & Reverse (R)1: ACAAAACATACCCTAAATAACCAATAAAC \\
\hline & F2: AATATGGAGAGGGATAGATAGGAGGA \\
\hline & R2: ACTCTTACTAATAAAAAAACTCATAACAA \\
\hline \multirow[t]{4}{*}{$F O S B$} & F1: TTGATGTTATTGTTAGGATATTAAATAAATATTT \\
\hline & R1: AAATCTTTCCAAАAАCTTTCTCCC \\
\hline & F2: GGGAGAAAGTTTTTGGAAAGATTT \\
\hline & R2: CCTAAACACAAAAAAACCCCTATAA \\
\hline \multirow[t]{8}{*}{ PCDH10 } & F1: GAGGTGTTGGATATTAATGATAATTTTT \\
\hline & R1: AACACATTATCATTAAAATCCAACACT \\
\hline & F2: AGTGTTGGATTTTAATGATAATGTGTT \\
\hline & R2: AAACCACCACAATACCGAACG \\
\hline & F3: CGTTCGGTATTGTGGTGGTTT \\
\hline & R3: TAAAAACTAAAATCCTTCAACTACTCATAAT \\
\hline & F4: ATTATGAGTAGTTGAAGGATTTTAGTTTTTA \\
\hline & R4: CCACCAACTAAACCACCAAAATAA \\
\hline \multirow[t]{10}{*}{ RASSF5 } & F1: TGAAGGAAGGGGAAATTTAATTAGAG \\
\hline & R1: TCTTCACCTAAAACAACTACAAAATTC \\
\hline & F2: GAATTTTGTAGTTGTTTTAGGTGAAGA \\
\hline & R2: CAATCTCTACTACAAACCAAAC \\
\hline & F3: GTTTGGTTTGTAGTAGAGATTG \\
\hline & R3: TACCCCAAAACCCTCCCAATCCTT \\
\hline & F4: TGATTTGTAGTTTTTTGAGTTTATTTGTTAT \\
\hline & R4: AAAAAAAATAAACACССCТCCC \\
\hline & F5: GGGAGGGGTGTTTATTTTTTTT \\
\hline & R5: TACAATACCCACTACTCATACTACTATCCA \\
\hline
\end{tabular}

Briefly, genomic DNA was extracted from cells and bisulfite DNA conversion was performed using a thermal cycler. Following this, the bisulfite converted DNA was purified and used for PCR analyses. Specific PCR products were recovered using a Gel Extraction Kit (Axygen) and cloned into pUCm-T vectors (Sangon) for sequencing. The primers in Table 2 were used to amplify target genes.

\section{Dot-blot assays}

In order to detect $5 \mathrm{hmC}$ levels in genomic DNA, we extracted DNA, and sample concentrations were adjusted. DNA samples were denatured at $99^{\circ} \mathrm{C}$ for $10 \mathrm{~min}$, and immediately cooled on ice. The resulting DNA was bound to a nitrocellulose membrane, air dried, and cross-linked using the UV light. Immunoblotting was performed using the anti-5hmC antibodies followed by the incubation with horseradish-peroxidase-linked secondary antibodies.

\section{Statistical analysis}

All results are reported as mean \pm standard error of mean (SEM). Each experiment was performed in triplicate and was repeated at least three times. The results obtained in two experimental groups were compared by two-tailed unpaired Student's t tests. $\mathrm{p}<0.05, \mathrm{p}<0.01$, and $\mathrm{p}<0.001$ were considered statistically significant, and are indicated in the figures by one, two, and three asterisks, respectively.

\section{Author's contributions}

WWP and HYF designed the research, analyzed data, and wrote the manuscript; BTL performed the 
experiments, assisted by CY, YX, and SBL. All authors discussed the results and provided comments on the manuscript.

\section{CONFLICTS OF INTEREST}

The authors declare that they have no potential conflicts of interest with the contents of this article.

\section{FUNDING}

This study was supported by theNational Natural Science Foundation of China (81402162), the Natural Science Foundation of Zhejiang Province (LY17H160060, LQ13H160020). "Supported by the grant of the 12th Five-year Plan for University Key Academic Subject (Pharmacology), Zhejiang Province".

\section{REFERENCES}

1. Giornelli GH. Management of relapsed ovarian cancer: a review. Springerplus. 2016; 5:1197. https://doi.org/10.1186/ s40064-016-2660-0.

2. Kudo Y, Tateishi K, Yamamoto K, Yamamoto S, Asaoka Y, Ijichi H, Nagae G, Yoshida H, Aburatani H, Koike K. Loss of 5-hydroxymethylcytosine is accompanied with malignant cellular transformation. Cancer Sci. 2012; 103:670-676. https://doi.org/10.1111/j.1349-7006.2012.02213.x.

3. Ooi SK, O'Donnell AH, Bestor TH. Mammalian cytosine methylation at a glance. J Cell Sci. 2009; 122:2787-2791. https://doi.org/10.1242/jcs.015123.

4. Holliday R, Pugh JE. DNA modification mechanisms and gene activity during development. Science. 1975; 187:226-232.5.

5. Brant JO, Riva A, Resnick JL, Yang TP. Influence of the Prader-Willi syndrome imprinting center on the DNA methylation landscape in the mouse brain. Epigenetics. 2014; 9:1540-15566. https://doi.org/10.4161/15592294.20 14.969667.

6. Klose RJ, Bird AP. Genomic DNA methylation: the mark and its mediators. Trends Biochem Sci. 2006; 31:89-977. https://doi.org/10.1016/j.tibs.2005.12.008.

7. Baylin SB, Jones PA. A decade of exploring the cancer epigenome - biological and translational implications. Nat Rev Cancer. 2011; 11:726-734. https://doi.org/10.1038/ $\operatorname{nrc} 3130$

8. Choi JD, Lee JS. Interplay between Epigenetics and Genetics in Cancer. Genomics Inform. 2013; 11:164-173. https://doi.org/10.5808/GI.2013.11.4.164.

9. Guo JU, Su Y, Zhong C, Ming GL, Song H. Hydroxylation of 5-methylcytosine by TET1 promotes active DNA demethylation in the adult brain. Cell. 2011; 145:423-434. https://doi.org/10.1016/j.cell.2011.03.022.
10. Kaas GA, Zhong C, Eason DE, Ross DL, Vachhani RV, Ming GL, King JR, Song H, Sweatt JD. TET1 controls CNS 5-methylcytosine hydroxylation, active DNA demethylation, gene transcription, and memory formation. Neuron. 2013; 79:1086-1093. https://doi.org/10.1016/j. cell.2011.03.022.

11. Wu H, Zhang Y. Mechanisms and functions of Tet proteinmediated 5-methylcytosine oxidation. Genes Dev. 2011; 25:2436-2452. https://doi.org/10.1101/gad.179184.111.

12. Jin SG, Jiang Y, Qiu R, Rauch TA, Wang Y, Schackert G, Krex D, Lu Q, Pfeifer GP. 5-Hydroxymethylcytosine is strongly depleted in human cancers but its levels do not correlate with IDH1 mutations. Cancer Res. 2011; 71:73607365. https://doi.org/10.1158/0008-5472.CAN-11-2023.

13. Jin SG, Wu X, Li AX, Pfeifer GP. Genomic mapping of 5-hydroxymethylcytosine in the human brain. Nucleic Acids Res. 2011; 39:5015-5024. https://doi.org/10.1093/ nar/gkr120.

14. Lian CG, Xu Y, Ceol C, Wu F, Larson A, Dresser K, Xu W, Tan L, Hu Y, Zhan Q, Lee CW, Hu D, Lian BQ, et al. Loss of 5-hydroxymethylcytosine is an epigenetic hallmark of melanoma. Cell. 2012; 150:1135-1146. https://doi. org/10.1016/j.cell.2012.07.033.

15. Liu C, Liu L, Chen X, Shen J, Shan J, Xu Y, Yang Z, Wu L, Xia F, Bie P, Cui Y, Bian XW, Qian C. Decrease of 5-hydroxymethylcytosine is associated with progression of hepatocellular carcinoma through downregulation of TET1. PLoS One. 2013; 8:e62828. https://doi.org/10.1371/journal. pone. 0062828 .

16. Yang H, Liu Y, Bai F, Zhang JY, Ma SH, Liu J, Xu ZD, Zhu HG, Ling ZQ, Ye D, Guan KL, Xiong Y. Tumor development is associated with decrease of TET gene expression and 5-methylcytosine hydroxylation. Oncogene. 2013; 32:663-669. https://doi.org/10.1038/onc.2012.67.

17. Ono R, Taki T, Taketani T, Taniwaki M, Kobayashi H, Hayashi Y. LCX, leukemia-associated protein with a CXXC domain, is fused to MLL in acute myeloid leukemia with trilineage dysplasia having $\mathrm{t}(10 ; 11)(\mathrm{q} 22 ; \mathrm{q} 23)$. Cancer Res. 2002; 62:4075-4080.

18. Lorsbach RB, Moore J, Mathew S, Raimondi SC, Mukatira ST, Downing JR. TET1, a member of a novel protein family, is fused to MLL in acute myeloid leukemia containing the t(10;11)(q22;q23). Leukemia. 2003; 17:637-641. https://doi. org/10.1038/sj.leu.2402834.

19. Sun $M$, Song CX, Huang $H$, Frankenberger CA, Sankarasharma D, Gomes S, Chen P, Chen J, Chada KK, He C, Rosner MR. HMGA2/TET1/HOXA9 signaling pathway regulates breast cancer growth and metastasis. Proc Natl Acad Sci U S A. 2013; 110:9920-9925. https:// doi.org/10.1073/pnas.1305172110.

20. Hsu CH, Peng KL, Kang ML, Chen YR, Yang YC, Tsai $\mathrm{CH}$, Chu CS, Jeng YM, Chen YT, Lin FM, Huang HD, Lu YY, Teng YC, et al. TET1 suppresses cancer invasion by activating the tissue inhibitors of metalloproteinases. 
Cell Rep. 2012; 2:568-579. https://doi.org/10.1016/j. celrep.2012.08.030.

21. Ko M, Huang Y, Jankowska AM, Pape UJ, Tahiliani M, Bandukwala HS, An J, Lamperti ED, Koh KP, Ganetzky R, Liu XS, Aravind L, Agarwal S, et al. Impaired hydroxylation of 5-methylcytosine in myeloid cancers with mutant TET2. Nature. 2010; 468:839-843. https://doi. org/10.1038/nature09586.

22. Pan WW, Zhou JJ, Yu C, Xu Y, Guo LJ, Zhang HY, Zhou D, Song FZ, Fan HY. Ubiquitin E3 ligase CRL4(CDT2/ DCAF2) as a potential chemotherapeutic target for ovarian surface epithelial cancer. J Biol Chem. 2013; 288:2968029691. https://doi.org/10.1074/jbc.M113.495069.

23. Oladghaffari M, Islamian JP, Baradaran B, Monfared AS. MLN4924 therapy as a novel approach in cancer treatment modalities. J Chemother. 2016; 28:74-82. https://doi.org/10 .1179/1973947815Y.031681R10066.

24. Ciccarone F, Valentini E, Zampieri M, Caiafa P. $5 \mathrm{mC}$-hydroxylase activity is influenced by the PARylation of TET1 enzyme. Oncotarget. 2015; 6:24333-24347. https:// doi.org/10.18632/oncotarget.4476.

25. Allen NP, Donninger H, Vos MD, Eckfeld K, Hesson L, Gordon L, Birrer MJ, Latif F, Clark GJ. RASSF6 is a novel member of the RASSF family of tumor suppressors. Oncogene. 2007; 26:6203-6011. https://doi.org/10.1038/ sj.onc. 1210440 .

26. Vos MD, Dallol A, Eckfeld K, Allen NP, Donninger H, Hesson LB, Calvisi D, Latif F, Clark GJ. The RASSF1A tumor suppressor activates Bax via MOAP-1. J Biol Chem. 2006; 281:4557-4563. https://doi.org/10.1074/jbc. M512128200.

27. Helmbold P, Richter AM, Walesch S, Skorokhod A, Marsch WCh, Enk A, Dammann RH. RASSF10 promoter hypermethylation is frequent in malignant melanoma of the skin but uncommon in nevus cell nevi. J Invest Dermatol. 2012; 132:687-694. https://doi.org/10.1038/jid.2011.380.

28. Ricciardelli C, Oehler MK. Diverse molecular pathways in ovarian cancer and their clinical significance. Maturitas. 2009; 62:270-275. https://doi.org/10.1016/j. maturitas.2009.01.001.

29. Li L, Li C, Mao H, Du Z, Chan WY, Murray P, Luo B, Chan AT, Mok TS, Chan FK, Ambinder RF, Tao Q. Epigenetic inactivation of the CpG demethylase TET1 as a DNA methylation feedback loop in human cancers. Sci Rep. 2016; 6:26591. https://doi.org/10.1038/srep26591.

30. Yu C, Zhang YL, Pan WW, Li XM, Wang ZW, Ge ZJ, Zhou JJ, Cang Y, Tong C, Sun QY, Fan HY. CRL4 complex regulates mammalian oocyte survival and reprogramming by activation of TET proteins. Science. 2013; 342:15181521. https://doi.org/10.1126/science. 1244587.

31. Neri F, Dettori D, Incarnato D, Krepelova A, Rapelli S, Maldotti M, Parlato C, Paliogiannis P, Oliviero S. TET1 is a tumour suppressor that inhibits colon cancer growth by derepressing inhibitors of the WNT pathway. Oncogene. 2015; 34:4168-4176. https://doi.org/10.1038/onc.2014.356.

32. Zelic R, Fiano V, Grasso C, Zugna D, Pettersson A, Gillio-Tos A, Merletti F, Richiardi L. Global DNA hypomethylation in prostate cancer development and progression: a systematic review. Prostate Cancer Prostatic Dis. 2015; 18:1-12. https://doi.org/10.1038/pcan.2014.45.

33. Wu Y, Zhang X, Lin L, Ma XP, Ma YC, Liu PS. Aberrant methylation of RASSF2A in tumors and plasma of patients with epithelial ovarian cancer. Asian Pac J Cancer Prev. 2014; 15:1171-1176.

34. Ding JJ, Wang G, Shi WX, Zhou HH, Zhao EF. Promoter Hypermethylation of FANCF and Susceptibility and Prognosis of Epithelial Ovarian Cancer. Reprod Sci. 2016; 23:24-30. https://doi.org/10.1177/1933719115612136.

35. Kumari G, Singhal PK, Suryaraja R, Mahalingam S. Functional interaction of the Ras effector RASSF5 with the tyrosine kinase Lck: critical role in nucleocytoplasmic transport and cell cycle regulation. J Mol Biol. 2010; 397:89-109. https://doi.org/10.1016/j.jmb.2010.01.005.

36. Park J, Kang SI, Lee SY, Zhang XF, Kim MS, Beers LF, Lim DS, Avruch J, Kim HS, Lee SB. Tumor suppressor ras association domain family 5 (RASSF5/NORE1) mediates death receptor ligand-induced apoptosis. J Biol Chem. 2010; 285:35029-35038. https://doi.org/10.1074/jbc. M110.165506.

37. Calvisi DF, Donninger H, Vos MD, Birrer MJ, Gordon L, Leaner V, Clark GJ. NORE1A tumor suppressor candidate modulates p21CIP1 via p53. Cancer Res. 2009; 69:46294637. https://doi.org/10.1158/0008-5472.CAN-08-3672.

38. Richter AM, Haag T, Walesch S, Herrmann-Trost P, Marsch WC, Kutzner H, Helmbold P, Dammann RH. Aberrant Promoter Hypermethylation of RASSF Family Members in Merkel Cell Carcinoma. Cancers (Basel). 2013; 5:15661576. https://doi.org/10.3390/cancers5041566.

39. Orr BA, Haffner MC, Nelson WG, Yegnasubramanian $\mathrm{S}$, Eberhart CG. Decreased 5-hydroxymethylcytosine is associated with neural progenitor phenotype in normal brain and shorter survival in malignant glioma. PLoS One. 2012; 7:e41036. https://doi.org/10.1371/journal.pone.0041036.

40. Tian Y, Pan F, Sun X, Gan M, Lin A, Zhang D, Zhu Y, Lai M. Association of TET1 expression with colorectal cancer progression. Scand J Gastroenterol. 2017; 2:312-320. https://doi.org/10.1080/00365521.2016.1253767.

41. Lv L, Zhang T, Yi Q, Huang Y, Wang Z, Hou H, Zhang H, Zheng W, Hao Q, Guo Z, Cooke HJ, Shi Q. Tetraploid cells from cytokinesis failure induce aneuploidy and spontaneous transformation of mouse ovarian surface epithelial cells. Cell Cycle. 2012; 11:2864-2875. https://doi.org/10.4161/ cc. 21196 . 